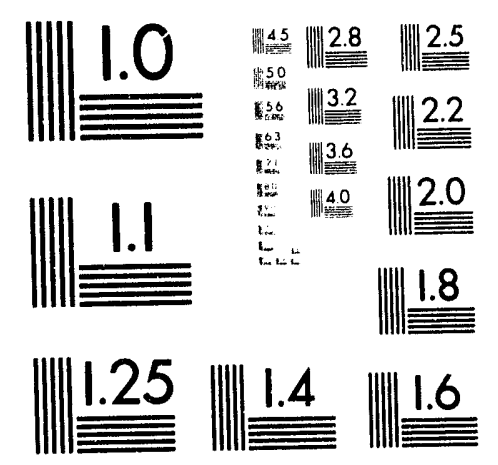



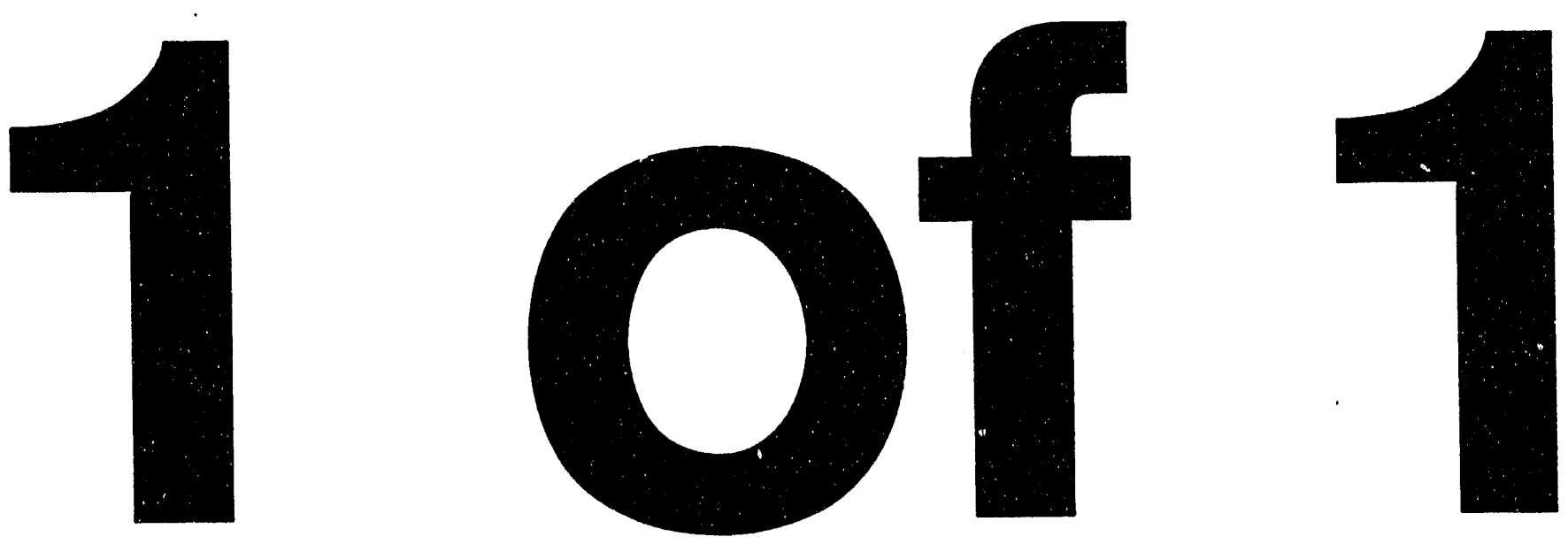
Presented at the 1993 International Industrial Symposium on the Super Collider, San Francisco, CA May 6-8, 1993

\title{
QUENCH PROPAGATION STUDY FOR BNL-BUILT, FULL-LENGTH, 50mm APERTURE SSC MODEL DIPOLES
}

\author{
J. Muratore, M. Anerella, G. Cottingham, M. Garber, G. Ganetis, A. Ghosh, \\ A. Greene, R. Gupta, S. Kahn, E. Kelly, G. Morgan, A. Prodell, W. Sampson, \\ R. Shutt, P. Thompson, P. Wanderer and E. Willen
}

Brookhaven National Laboratory', Upton, NY 11973

\section{INTRODUCTION}

As part of the program to build and test SSC $50 \mathrm{~mm}$ aperture prototype dipole magnets, a series of seven full-length (15m-long) dipoles were built and tested at BNL. The design of these magnets and their differences from the earlier $40 \mathrm{~mm}$ aperture dipole magnets have been discussed elsewhere ${ }^{[1]}$. In order to thoroughly evaluate the performance of the new design, an extensive and varied schedule of tests were done, and these included quench testing and stress measurements to exhibit mechanical and thermal behavior, a ramp rate quench program to study eddy current heating effects in the conductors, and a multitude of magnetic field measurements to characterize field quality.

An important part of the testing program was the study of quench propagation velocity and hot spot temperature over a range of experimental conditions in order to characterize the safety of the conductor during quenches experienced under different circumstances. Such studies are important tools in the design, implementation, and verification of quench protection strategies in superconducting accelerator magnets. This investigation was facilitated by artificially inducing quenches under controlled experimental conditions with spot heaters placed at carefully chosen locations on the magnet coils. Such studies were done as part of the $15 \mathrm{~m}$-long magnet test program and were performed on five of the magnets in the series. All were equipped with spot heaters on an inner coil, and two of these also had spot heaters on an outer coil. Therefore, in addition to the usual studies in the inner coils, where most spontaneous quenches originate, it was also possible to study quench propagation in the outer coils, where slower quench velocities and higher conductor temperatures are expected, in comparison to that in the inner coils. In addition, the two magnets with outer coil spot heaters were the only ones in the series which used the new all-Kapton cablí insulation scheme, so such a study would provide valuabie data about the thermal flow characteristics of this insulation during quenches.

In spontaneous quenches, where there may be no voltage taps, it is not possible to measure the conductor hot spot temperature. It is very straightforward, however, to measure the number of MIITs generated, since only the magnet current and voltage need be measured. The concept of MIITs then becomes a valuable diagnostic tool which can characterize the temperature behavior of a conductor during quench and can be used to determine limits for safe operation of the coil. With spot heaters placed at known locations and closely bracketed by voltage taps, hot spot temperature can be measured. Research such as is described in this paper is therefore important in order to determine the validity of the MIITs approach and to establish a correlation between temperature and MIITs. 


\section{DISCLAIMER}

This report was prepared as an account of work sponsored by an agency of the United States Government. Neither the United States Government nor any agency thereof, nor any of their employees, makes any warranty, express or implied, or assumes any legal liability or responsibility for the accuracy, completeness, or usefulness of any information, apparatus, product, or process disclosed, or represents that its use would not infringe privately owned rights. Reference herein to any specific commercial product, process, or service by trade name, trademark, manufacturer, or otherwise does not necessarily constitute or imply its endorsement, recommendation, or favoring by the United States Government or any agency thereof. The views and opinions of authors expressed herein do not necessarily state or reflect those of the United States Government or any agency thereof. 


\section{MAGNET DESIGN AND CONSTRUCTION}

The BNL-built, full-length $50 \mathrm{~mm}$ aperture dipole magnets all shared the same design and construction features. They differed only in cable conductor and insulation parameters, the most important of which are listed in Table 1 for selected magnet coils. In all cases, spot heaters were mounted on the midplane turn of the lower coils only, and information for only those coils for which spot heater studies were done are included in the table. As can be seen, the conductor, for which there were three industry suppliers, varied to some extent in critical current, copperto-superconductor ratio, and RRR. In particular, the lower inner coil cable for DCA207 had a post-cure RRR of 222, compared to the nominal value of about 135 for the other inner coils; and the copper-to-superconductor ratio of the lower inner coil of DCA208 was 1.34, lower than the nominal 1.5 for the other inner coils. Note that the last two magnets in the series, DCA212 and DCA213, had Kapton-Kapton cable wrap, which resulted in higher curing temperatures and pressures.

\section{EXPERIMENTAL PROCEDURES}

Each spot heater element is a $50.8 \mu \mathrm{m}$ thick rectangular strip of stainless steel $38.1 \mathrm{~mm}$ long and $11.9 \mathrm{~mm}$ wide, mounted on the wide flat dimension of cable on a section of the midplane turn. The mounting is accomplished by first stripping away a $50.8 \mathrm{~mm}$ length of cable insulation at the location where the heater is to be attached, then placing two layers of Kapton, the heater element strip, then another layer of Kapton. In addition to this, there is a Kapton cap placed over the midplane of both the lower and upper coils. Projections on each end of the heater element strip are bent away from the cable and brought out into leads, which are routed along the coil inner diameter to the outside of the magnet for connection to a pulser power supply. A quench is initiated by generating a pulse by capacitative discharge through the heating element with enough energy to heat the small section of conductor to its critical temperature. Energies needed to quench depended on the field strength, and therefore magnet current, at the quench location. For the inner coils, spot heater energies ranged up to $17 \mathrm{~J}$, while for the outer coils, energies were as high as $80 \mathrm{~J}$.

Table 1. Coil cable and cure parameters related to quench performance for those magnet coils involved in the study.

\begin{tabular}{|c|c|c|c|c|c|c|c|c|c|}
\hline Magnet & Coil & $\begin{array}{c}\text { Cable } \\
\text { ID }\end{array}$ & $\begin{array}{l}\text { Wire } \\
\text { Mfg. }\end{array}$ & $\begin{array}{l}I_{c}(A) \\
{[7.0 \mathrm{~T}]} \\
\end{array}$ & $\begin{array}{l}\text { Cu:SC } \\
\text { Ratio } \\
\end{array}$ & $\begin{array}{l}\text { RRR } \\
\text { Post } \\
\text { Cure } \\
\end{array}$ & $\begin{array}{l}\text { Cable } \\
\text { Wrap } \\
\end{array}$ & $\begin{array}{c}\text { Cure T } \\
(\mathrm{C})\end{array}$ & $\begin{array}{l}\text { Cure P } \\
(\mathrm{MPa}) \\
\end{array}$ \\
\hline DCA207 & LI & SSC-3-I-00055 & IGC & 10836 & 1.54 & 222 & $\mathrm{~K} / \mathrm{EF}$ & 135 & 73.1 \\
\hline DCA208 & LI & SSC-3-I-00067 & IGC & 11371 & 1.34 & 132 & $\mathrm{~K} / \mathrm{EF}$ & 135 & 73.1 \\
\hline DCA211 & LI & SSC-3-O-00050 & OST & 11283 & 1.48 & & $\mathrm{~K} / \mathrm{EF}$ & 135 & 49.0 \\
\hline DCA212 & $\begin{array}{l}\text { LI } \\
\text { LO }\end{array}$ & $\begin{array}{l}\text { SSC-3-S-00034 } \\
\text { SSC-4-S-00027 }\end{array}$ & $\begin{array}{l}\text { SCN } \\
\text { SCN }\end{array}$ & $\begin{array}{r}10368 \\
6924\end{array}$ & $\begin{array}{l}1.51 \\
1.77\end{array}$ & $\begin{array}{l}136 \\
228\end{array}$ & $\begin{array}{l}K / K \\
K / K\end{array}$ & $\begin{array}{l}225 \\
225\end{array}$ & $\begin{array}{l}81.4 \\
80.7\end{array}$ \\
\hline DCA213 & $\begin{array}{l}\text { LI } \\
\text { LO }\end{array}$ & $\begin{array}{l}\text { SSC-3-S- }-00040 \\
\text { SSC-4-S-00028 }\end{array}$ & $\begin{array}{l}\text { SCN } \\
\text { SCN }\end{array}$ & $\begin{array}{r}10039 \\
6832\end{array}$ & $\begin{array}{l}1.54 \\
1.78\end{array}$ & $\begin{array}{l}140 \\
221\end{array}$ & $\begin{array}{l}K / K \\
K / K\end{array}$ & $\begin{array}{l}225 \\
225\end{array}$ & $\begin{array}{l}81.4 \\
82.7\end{array}$ \\
\hline
\end{tabular}

$\mathrm{K} / \mathrm{EF}=\mathrm{Kapton} /$ Epoxy-Fiberglass cable insulation scheme; $\mathrm{K} / \mathrm{K}=\mathrm{Kapton} / \mathrm{Kapton}$ cable insulation scheme; LI = Lower inner; LO = Lower outer.

For each of the magnets, two spot heaters were mounted on the midplane turn of the lower inner coil: spot heater $\# 1$ was located $68.58 \mathrm{~cm}$ from the lead end; spot heater $\# 2$ was $22.86 \mathrm{~cm}$ from the nonlead end and was $13.81 \mathrm{~m}$ from a voltage tap pair on the same straight section of cable. For a quench from spot heater $\$ 2$, therefore, the time-of-flight of the quench front from the quench origin at the spot heater to the tap pair was used to calculate the average quench velocity along the straight section of cable. In DCA212 and DCA213, the magnets employing the all-Kapton insulation scheme, there were also two spot heaters on the midplane turn of the lower outer coil: spot heaters $\# 3$ and $\# 4$ were $7.62 \mathrm{~cm}$ from the lead and nonlead ends, respectively. Both these heaters were each closely bracketed by voltage taps spaced $10.16 \mathrm{~cm}$ apart with the spot heater at the center.

For the outer coil spot heaters with their bracketing voltage taps, conductor hot spot 
temperature was measured during a quench by acquiring the voltage signal vs time during the quench event and dividing this signal by the magnet current, point-by point. From the resulting time development of the conductor resistance, the temperature could be determined by using a resistance-temperature calibration curve obtained by measurements made on a short sample of the cable used in the outer coils ${ }^{[2]}$.

MITTs values for each quench were calculated for both inner and outer coil spot heater quenches by integrating the square of the acquired current signal waveform from the quench start time, determined by the onset of resistive voltage, to the time at which the magnet current has decayed to zero. The relationship between MIITs and hot spot temperature is given by the expression

$$
\text { MIITS } \times 10^{6}-\int_{0}^{-} d t I^{2}(t)-S^{2} \int_{T_{0}}^{T_{\max }} d T\left(\frac{r}{1+r}\right) \frac{C(T)}{\rho(R R R, T, B)}
$$

which is derived from a heat balance equation ${ }^{[3]}$ that assumes adiabatic and constant field conditions, usually good assumptions during the initial part of the quench propagation. In this equation, $T_{0}$ is the initial temperature, $T_{\max }$ is the hot spot temperature, $S$ is the conductor cross-section, $\mathrm{C}$ is the specific heat per unit volume of conductor, $\mathrm{B}$ is the magnetic field at the quench spot, $\rho$ is the copper resistivity, and $r$ is the copper-to-superconductor ratio.

As can be seen, if the conductor properties and the magnetic field at the quench location are known, the temperature can be calculated from MIITs by an implicit solution of Eq. 1. A computer model which does this was used to generate families of MIITs-temperature correlation curves, for both the inner and the outer coils, for a range of magnetic fields ${ }^{(4)}$. These theoretical calculations have two purposes: to establish upper bounds for MIITs that give the safe conductor temperature limits of, typically, 500K; and to determine if MIITs and temperature measurements during quenches, such as were done on the outer coils, fit the adiabatic model and its assumptions. Doing this may give insight into the actual mechanisms occurring during quench propagation.

In addition to temperature and MIITs measurements, quench propagation velocities were also calculated from the voltage signal data and fitted to an adiabatic model ${ }^{(5)}$ to obtain information on mechanisms at work during quenches. Velocity may be calculated from the quench signals in two ways. If the quench occurs in a section of cable between two voltage taps, as it does for the outer coil spot heaters, or if the quench occurs at a known distance from a single tap, as it does for the: inner coil spot heater $\# 2$, the time of flight to these taps can be used to calculate velocity and position. Such a calculation results in the average velocity over the length of the section. It the quench front is accelerating, this will be different from the initial velocity of the quench but this is the most important value from the standpoint of temperature and MIITs ge.lerated.

If the copper resistivity $\rho(B)$ is known as a function of magnetic field $B$, the initial velocity can be calculated by measuring the slope $\mathrm{dV} / \mathrm{dt}$ of the resistive voltage increase with time and using the formula

$$
v_{\text {ints }}-\frac{S}{\rho(B) I} \frac{d V}{d t}
$$

which can be derived from Ohm's Law and where $S$ is the cross-sectional area of the conductor and $I$ is the quench current.

For spot heater $\# 2$ in the inner coils of all five magnets and spot heater $\# 3$ in the outer coils of DCA212 and DCA213, quenches were induced at a series of currents and the MIITs values calculated. Then, in each of these cases, a series of quenches were initiated with increasing quench protection heater (strip heater) time delays at a selected current, usually that for which the MIITs number was a maximum. For the outer coil quenches, the hot spot temperature was determined from measurements of resistance vs. time and quench propagation velocities were calculated from time-of-flight measurements of voltage tap signals. For the inner coil quenches, average velocities were calculited by time-of-flight and initial velocities from Eq. 2. Results were compared to theoretical calculations of temperature from MIITs and of the initial quench velocities from adiabatic models to determine the validity of the models and their usefulness as predictive tools in quench testing. All test results reported here wcre done nominally at the SSC operating temperature of $4.35 \mathrm{~K}$.

\section{EXPERIMENTAL RESULTS}

1. MIITS

Quenches were induced at a series of magnet currents and, for each magnet, a plot of MIITs vs. $I_{q}$ was generated. Figure 1 shows these plots for the lower inner coil quenches of all five magnets. As can be seen, the shapes of the plots are similar, and they agree qualitatively with 
those studies done on earlier magnets in the SSC and RHIC projects. The current for peak MIITs ranged from $54 \%$ to $68 \%$ of the spontaneous plateau quench current. This behavior is typical and can be understood by a simple argument. Peak MIITs occurs at an intermediate current, at which the quench velocity has become fast enough to transport the heat away from the hot spot and limit the temperature there as stored electromagnetic energy is converted to heat. This current is typically about $2 / 3$ of the quench plateau mean value. Offsets a' vong the MIITs vs. quench current curves reflect differences in conductor properties among the $f_{1}$ ve magnets, as was shown in Table 1. Note that the two all-kapton magnets DCA212 and DCA213 exhibit the highest MIITs curves. It will be seen later that the initial quench propagation velocities are slightly less for these magnets than for the others. Note also that the curve for DCA212 is higher than that for DCA213 even though they use similar conductor. This is due to a higher quench detection threshold used for DCA212 and so resulted in a longer delay between the start of quench and the time at which the power supply is shut off and the strip heaters are fired.

For DCA213, Fig. 1 also shows the MIITs as a function of current for the outer coil spot heater \#3, and, as for the inner coil data, MIITs values increase with current and reach a peak value, but much closer to the conductor short sample cable limit, about $93 \%$.

Studies were also done to determine if the magnet coils were self-protecting during quenches under conditions of maximum MIITs and, therefore, maximum hot spot temperature. This was done by inducing a series of quenches at the current of peak MIITs while incre ssing the time delay for strip heater firing after power supply shutoff. Figure 2 shows the results of this study for four of the masnets and plots MIITs vs strip heater time delay for each of the magnets at the current at which it exhibited peak MIITs during the previous study of MIITs variation with quench current. Except in the case of DCA213 inner coil data, the increasing MIITs numbers approach an asymptotic value and level off, as is expected in a self-protecting system. For DCA213, more data needed to be taken at longer time delays to determine the asymptotic MIITs value. For inner coils, the peak MIITs number reached during these studies corresponds to a temperature no higher than $302 \mathrm{~K}$, as calculated from Eq. 1, which provides an upper bound for hot spot temperature as a function of MIITs and magnetic field at the quench origin. These results show that the inner coil quenches generate hot spot temperatures below $500 \mathrm{~K}$ and are within safe limits. For the outer coil quenches of DCA213, data at $6000 \mathrm{~A}$ asymptotically approach a limit, as with the inner coil behavior, but this limit corresponds to a measured temperature of about $700 \mathrm{~K}$, which is considered to be above the safe limit. These results therefore indicate a need for strip heater protection for the outer coil conductor in DCA213.

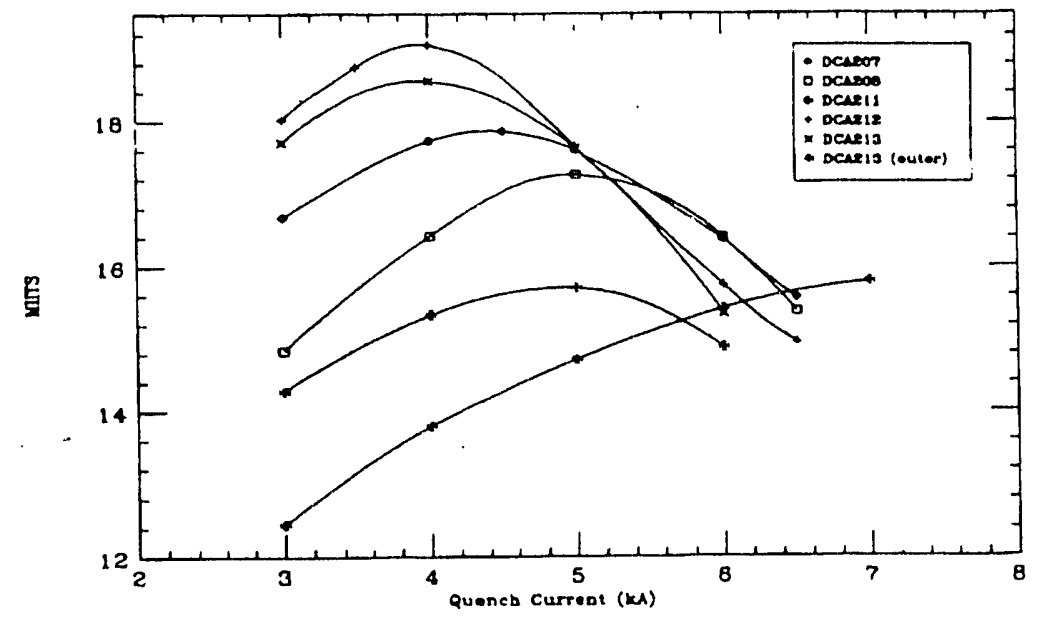

Figure 1. MIITs vs. quench current for magnets in spot heater studies. Quench detector threshold was $0.5 \mathrm{~V}$ for DCA213 (outer), $4 \mathrm{~V}$ for DCA212, and $2 \mathrm{~V}$ for all others.

\section{Quench Velocity}

For the inner coil quenches with spot heater $\# 2$, the average quench velocity through the midplane turn straight section of cable was calculated by time-of-flight for the quench front to reach the tap closest to the heater. This was done for different currents and the results were similar for all five magnets. The average over the five magnets is plotted against current in Fig. 3. It should be noted that the average velocities for the two all-Kapton magnets were similar to those for the other magnets, whereas the initial velocities were less for the all-Kapton magnets. 


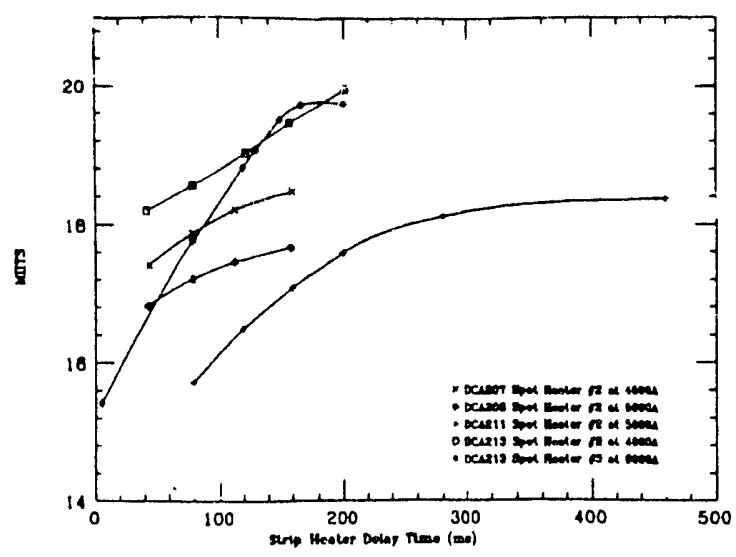

Figure 2. MIITs vs. strip heater delay.

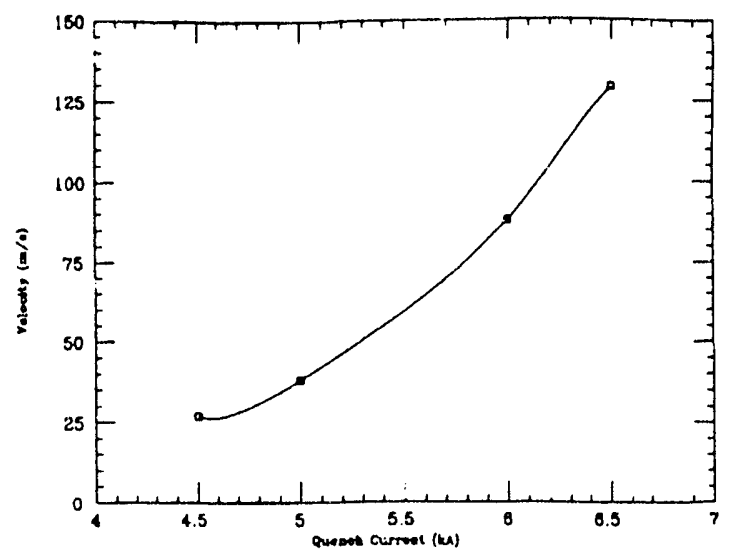

Figure 3. Average quench velocity vs. quench current for inner coil midplane turn.

Initial quench velocities were calculated with Eq. 2, using the slopes of the quench voltage signals. Data for DCA208 is shown in Fig.4, along with a theoretical curve of velocity vs. quench current calculated from a classical model that assumes no energy transfer by cooling and no change in magnetic field during the quench process ${ }^{[\mathfrak{I}]}$. The calculation also does not correct for temperature dependence of the specific heat and thermal conductivity of materials. In reality, some or all of these factors may be significant, and, for the all-Kapton magnets, this may be the case. Also, in some cases, the model may be valid only over the time span of the initial quench process. As with DCA208, the data fit the model predictions very closely in the case of the other epoxy-fiberglass wrap magnets; but, for the two all-Kapton magnets, the data fall below the model curves, as shown for DCA212 in Fig. 5. This implies that at least one of the assumptions in the model are not valid. In particular, this could reflect a larger cooling process than expected, and more cooling than in the epoxy-fiberglass wrap magnets.

Initial quench velocities for outer coil quenches were calculated by time of flight to the two closely bracketing voltage taps. Velocities ranged from about $5 \mathrm{~m} / \mathrm{s}$ at $3000 \mathrm{~A}$ to about $10 \mathrm{~m} / \mathrm{s}$ at $7000 \mathrm{~A}$.

\section{Hot Spot Temperature}

Since the outer coil spot heaters were the only ones which were closely bracketed by voltage taps, these were the only spot heaters for which we could directly measure the temperature of the quench hot spot and therefore quench studies with these heaters provided valuable temperature data for the determination of quench safety criteria in the superconductor. Also, the resulting MIITs-temperature correlation provided a check of the adiabatic MIITs model represented by Eq.1.

Due to problems with the quench detector circuitry, outer coil $\mathcal{C}$ ta from DCA212 is difficult to interpret and will not be presented here. For DCA213, hot spot emperature was determined by measuring the increase in resistance of the $10.16 \mathrm{~cm}$ length of cat:e between the voltage taps which bracket the spot heater, as was described earlier, and using short sample cable data of resistance vs. temperature. Temperatures can be plotted vs. MIITs values for all quenches performed but quenches were done at different magnet currents and therefore at correspondingly different magnetic fields, which varied from $0.58 \mathrm{~T}$ to $1.36 \mathrm{~T}$ at the midplane, as current was varied from $3 \mathrm{kA}$ to $7 \mathrm{kA}$, respectively. Since the MIITs-temperature correlation depends on the field at the quench location, all this data cannot be compared to a unique correlation curve generated by Eq. 1, since a different curve will result for each field at quench. However, since seven quenches were done at $6 \mathrm{kA}(1.16 \mathrm{~T})$ for one of the strip heater time delay studies, as was shown in Fig. 2, these data can be plotted against a theoretical MIITs-temperature curve calculated from Eq. 1 for that field. As can be seen in Fig. 6, the measured data points appear to diverge from the calculated curve as MIITs and T increase. This is to be expected in the case of an adiabatic model such as that used here. This curve can thus serve as an upper bound for temperatures if the MIITs values during a quench are known. 


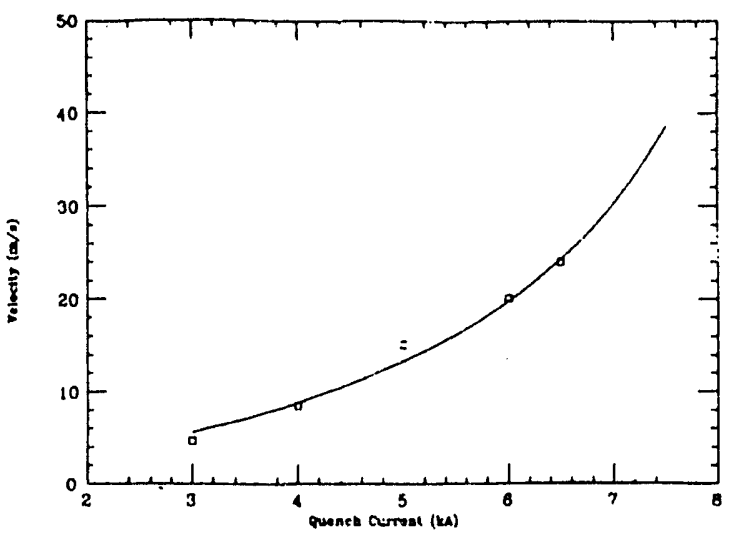

Figure 4. Initial quench velocity vs. quench current in inner coil midplane turn of DCA208. Solid curve is from model calculation.

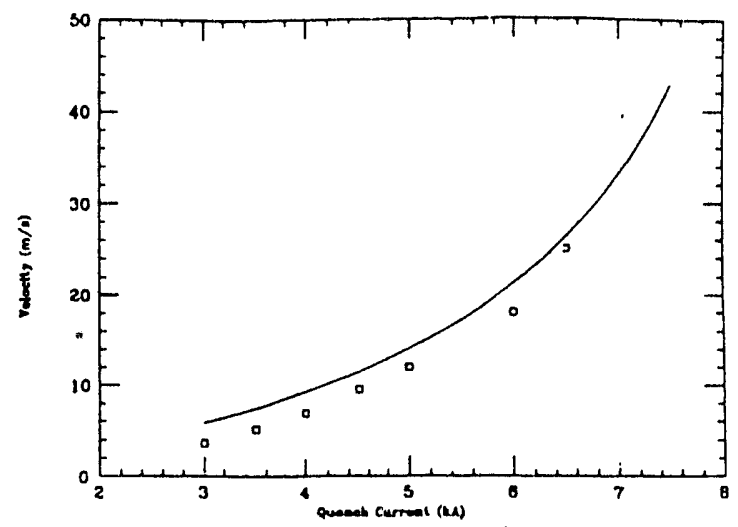

Figure 5. Initial quench velocity vs. quench current in inner coil midplane turn of DCA212. Solid curve is from model calculation.

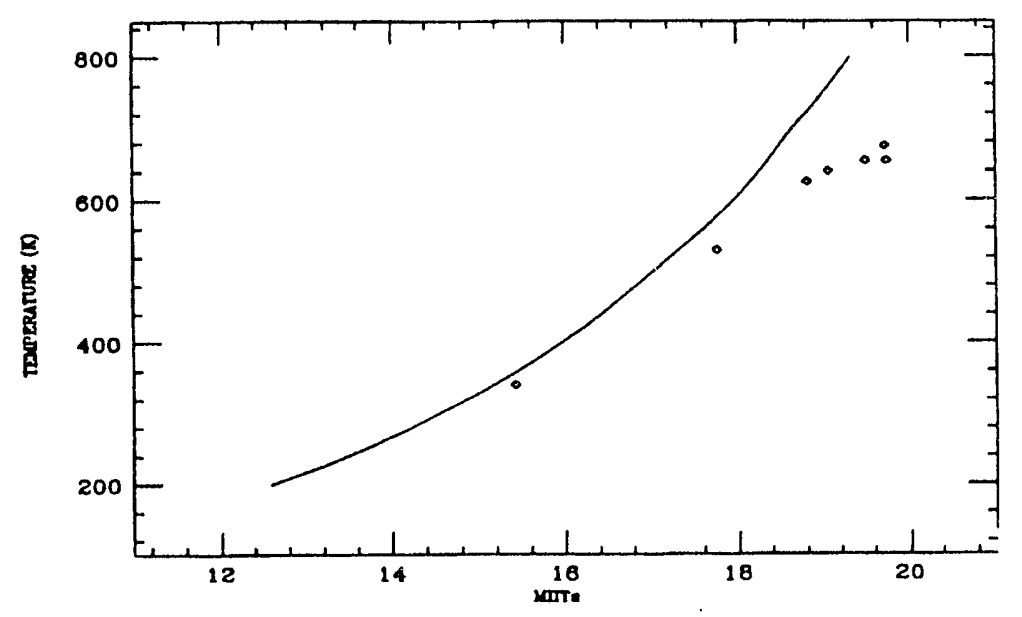

Figure 6. MIrTs-temperature correlation curve from adiabatic model, with data from DCA213.

\section{CONCLUSION}

Since it is not usually possible to measure hot spot temperature directly but it is straightforward to calculate the MIITs numbers, these results show that correlation curves generated by the adiabatic model are still useful as upper bounds for MIITs values when temperatures cannot be measured. In order to get a more realistic fit to the data and be a better predictor of quench temperature, a model must take into account various effects, which include: 1) cooling by transfer of heat to the helium; and 2) changes in the magnetic field at the quench location during the time scale of the quench".

Also, this study has shown that the inner coils are self-protecting but that the outer coils, with the type of conductor being used, may not be and may require strip heaters or some alternate protection scheme in case of quenches.

\section{REFERENCES}

[1] J.F. Muratore et al., "Construction and Test Results from $1.8 \mathrm{~m}$-Long, $50 \mathrm{~mm}$ Aperture SSC Model Collider Dipoles," Supercollider 4, p.559, Plenum Press, 1992.

[2] M. Garber, private communication.

[3] N.M. Wilson, Superconducting Magnets, Oxford Clarendon Press, p.200, 1983.

[4] A. Devred, MAGLIB Scientific Subroutine Library, Superconducting Supercollider Laboratory, 1992.

[5] A. Devred, "General Formulas for the Adiabatic Propagation Velocity of the Normal Zone," IEEE Trans. Magnetics, 25(2), 1698 (1989). 

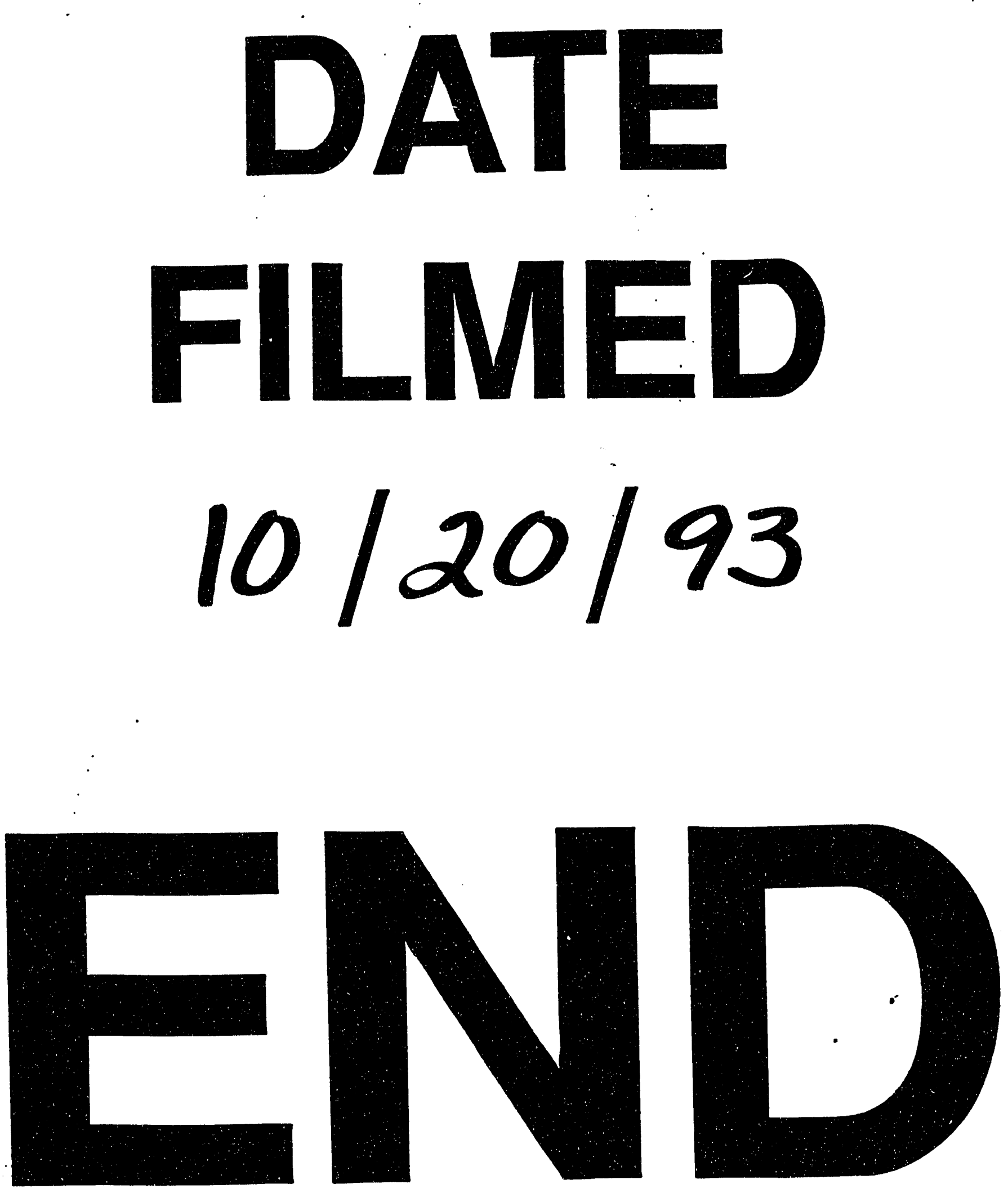
